\title{
Cultural Diversity and Its Influence on Role Players in a Full- Service School in Soshanguve: A Wellness Perspective
}

\author{
Ute Steenkamp
}

\section{Abstract}

The purpose of the study was to explore the role cultural diversity plays in a FullService School in Soshanguve by means of a wellness perspective lens. The phenomenon at hand was the way that cultural diversity influences role players within a Full-Service School. The study was underpinned by three theories, namely Hettler's Wellness Theory, Cultural-Historical Activity Theory and Ubuntu to generate a comprehensive insight into the role of cultural diversity on role players within a Full-Service School in Soshanguve. The study was premised on a qualitative philosophy using an interpretive paradigm, an ethnographic case study and using various qualitative methods of data collection, analysis and interpretation of data. Only one school participated in this research study as the goal of this research study was understanding the phenomenon from the participants' perspective. The study employed a purposive sampling approach to select diary entries from educators who participated in the semi-structured interviews. Data collection and analysis were precise as the data was collected and transcribed as soon as it was recorded. The researcher consequently decided to use thematic analysis to draw on the theoretical framework of this study. Thematic analysis refers to the identification of themes and patterns of meaning throughout the data in correlation to the research question. Thus, the researcher analysed content by coding specific themes as directed by the research project's theoretical framework. Among the findings was that role players identified that cultural diversity influences the wellness dimensions holistically. One of the recommendations is to establish a cultural awareness model in collaboration with the community within a Full-service school.

Keywords: full-service school, school governing bodies, cultural-historical activity theory, education management, culture, ubuntu, inclusive education

\section{Introduction}

This study explored cultural diversity and its role in a Full-Service School. The increasing cultural diversity in educational institutions forces that role players teach and manage learners and teachers with cultures, languages and backgrounds that are unknown to them. This study focused on the role cultural diversity might play on role players within a FullService School.

To understand cultural diversity, the researcher first defined culture and how theorists who studied culture define its many forms. Cultural diversity was then discussed, and the researcher looked at various studies to explore the role it may/may not play in educational environments. Culture is defined as distinct behavioural and social traits related to a certain 
group of people with their own religion, values, beliefs, and norms (Arnolds 2003). Matthew Arnolds (2003), who postulated that culture is not a homogenous social phenomenon, but divisible into numerous aspects emphasised the multifaceted, complex, and diverse nature of culture.

Cultural diversity is defined by Danso (2018) as the reality of a diversity of cultural or ethnic groups within a group and/or society. Cultural diversity has a correspondingly diverse impact on different aspects of the functionality of a school, firstly the teaching and learning process. According to Danso (2018) culture can influence the way in which the teachers teach and address cultural issues. In South Africa, teachers must teach and develop the learner as a whole, without considering their cultural heritage (South African Government 2009). Motitswe (2011) suggests that teachers might lead learners to feel excluded when an educator only focuses on one culture or cultural life experiences. Secondly, Motitswe (2011) concluded that culture may also lead to language barriers in the learning process. McMahon et al. (2000) also stated that Full-Service Schools value the concept of cultural sensitivity whereas little progress has been made on devised culture-specific programmes to target ethnic minority learners. McMahon et al.'s study focused on Latin American learners. McMahon et al.'s (2000) study was significant to this research study as it is recognised that the education system should be culture-specific but there seems to be little progress on developing these programmes to target ethnic minority learners.

Harmon and Schafft (2018) stated that to promote the success of each learner, a school must develop a school culture and instructional plan beneficial to student learning and staff proficient growth (Harmon \& Schafft, 2018). Burton (1980) identified four types of academic culture as a worldwide establishment: the culture of the profession, the culture of the enterprise, the culture of discipline and finally the culture of the system. As stated by Burton (1980), the researcher focused on the cultural diversity in a school's context and the role thereof. Therefore, the following research question was posed:

Cultural diversity and its influence on role players in a Full-service School in Soshanguve: A Wellness Perspective?

In answering this question, the study contributes knowledge towards the understanding of cultural diversity and its influence on role players within a Full-service school. The findings of the study will have positive implications for both policy and practice on cultural diversity in schools and how, if necessary, could be improved or maintained.

\section{Conceptualising Cultural Diversity}

A Full-Service School is a school which has been developed to accommodate all learners from different backgrounds and cultures and its aim is to assist learners with special needs (Department of Education, 2001). Full-Service Schools are a relatively new phenomenon in South Africa but have gained significant traction and popularity since the 1994 elections (Department of Education, 2001). Apartheid had resulted in significant learner-deficits and great barriers to knowledge between respective cultures and although South Africa is now a free country, South Africans still deal with historical disadvantages that hamper learning.

The research in this study postulates that an individual's culture is the aggregate of everything acquired and experienced during his or her lifetime. Arnolds (1869), however, states that culture is innate to all human beings and something all people inherently possess. The two 
theories underscore the contrasting views on how culture could be defined. The characteristics of culture, according to Schein (1984), are as follows: observable artefacts that are visible, values as a level of awareness and underlying assumptions that are usually taken for granted. Hinde's (2004) research aimed to answer the question of how the underlying assumptions of teachers could influence the culture of a school and how change is accepted or objected to culture, thus culture can be theoretically objected to change.

Gay (2013) stress the importance of cultural diversity in a school or educational institution, but they also state how its importance is not recognised and valued as much as it should be. A Full-Service School is established according to the culture of the community, the Department of Education and by educators in the classroom setting. This is informally manifested through people's actions, cooperation, problem-solving and these factors sub-consciously shape the values, culture and norms of a Full-Service School. Ortega-Williams, Crutchfield and Hall (2019) state that culture is identified and characterised by truly embedded values and beliefs - some of which are common across various schools, but some of which are unique and provide a diverse sense of what, how and why things are done at the particular school. These distinct practices and methodologies consequently impel a unique study since no two FullService Schools will have the same cultures or location.

Maraña (2010), whose research correlates with Hettler's Wellness Theory (1976), states that cultural diversity can have an impact on all developmental phases. Developmental phases refer to the development of all wellness dimensions within education. From as early as the 1970s, cultural diversity has had an impact on relationships, education, and various other phases of education. Moreover, Matarasso (2007) highlights that culture can grow and develop people in various areas of life and wellness. Matarasso (2007) noted, however, that cultural expressions are true to one's own culture and that culture can unite people and nations and could improve dwindling population figures. Peterson and Deal (1998) posited that culture could also enhance a positive outcome on various areas such as wellness. According to Weeks (2012), there are two ways of learning within a cultural setting of a South African school and old cultural ways of learning are now replaced with social interaction between classrooms, schools and communities. Thus, Full-Service Schools will be the focal point in revealing the culture of learning in a culturally diverse school since these schools are the ideal representation of cooperation among and within different schools (Steenkamp, 2012) and communities.

Research conducted by Lindström and Eriksson (2010) highlighted a case study done by Turnbull $(1961,1972)$ on two different tribes in Africa which revealed a complete loss of cultural identity and rituals by the tribe forced into a modern society as it assimilated and adapted to the Western culture. This is also a pinnacle research point as to how cultural diversity might influence a Full-Service School. Furthermore, Taylor (2008) argue that one cannot discount the remnants of the Apartheid regime still fostered by certain cultures, educators, and learners within the school system in South Africa and how this influences the functionality of schools. Taylor also mentions that a culture of learning, truancy and disciplinary issues is still evident in South African schools, thus influencing the wellness of a school setting. Jenkins (1987), known for research on cultural influences in South African schools, clearly points out the cultural changes within South Africa over time. This cultural 
evolution should be investigated to establish the reasoning behind the establishment of the Full-Service School by the Department of Education.

There is a noted gap in the research on cultural diversity within Full-Service Schools and how such diversity is promoted and fostered, which this research may seek to identify and establish.

\section{Three Theories}

The Wellness Theory (Hetter 1979) identified six dimensions to support and improve the future wellness of a school. Wellness is a dynamic awareness and teaching aiming for a longer and more successful existence. The model comprises of six dimensions that are physical, emotional, intellectual, social, occupational, and spiritual wellness (Hettler, 1979). The wellness theory seeks the development of the whole person. This is important to understand and to understand how cultural diversity might influence these dimensions of role players within a FSS. Currently, in FSS not enough emphasis is placed on wellness and/or all the wellness dimensions. Without looking at the all wellness dimensions one might leave out pivotal information regarding cultural diversity's role on the wellness of role players. Ubuntu is a widely known and practiced philosophy in South Africa. Ubuntu became popular amongst South Africans in the 1950s and is seen as a concept for enhancing the development of postapartheid South Africa. Ubuntu as a theoretical framework will provide insight into how various cultures operate within a FSS. Ubuntu will also enhance the deciphering of interviews and observations with participants and it provides a basis for authentic research unique to the South African context. Unfortunately, the current position in schools regarding Ubuntu is seen as a political ideology which endorses equality and human rights for all. Ubuntu as a theory could be used to effectively develop a school culture of Ubuntu as it advocates for the inclusion of all races, diversities and cultures. The Cultural History Activity Theory (CHAT) (Vygotsky 1978) focused on the pivotal role it plays on individuals. This theory is important in this research as the research wants to understand the history of the role players' social culture and how it can be adjusted or improved and that it is the knowledge and familiarity with the culture itself which empowers the reinforcement of a positive cultural norm in a FSS.

\section{Methodology}

This qualitative study and the chosen research design was an Ethnographic case study. The aim of the ethnographic case study is to find and connect theory with practice, using one's own knowledge and research as a starting to point to understand people and learning about participants' role and work environment (Fairhurst and Good, 1991). Spradley (1979) stated that an ethnographic case study involves sourcing from participants' words and actions. Through an ethnographic case study the researcher wanted to understand the actions of participants by observing various cultures. According to Maree (2007), a case study can be defined as a first-hand experience of a contemporary phenomenon of the role cultural diversity plays within a FSS. Purposive sampling was used for this study. Only participants who were regarded as "data affluent" (Ames, Glenton and Lewin, 2019) were used. Purposive sampling has been identified by Ames et al. (2019) as selecting certain participants for a specific purpose, which streamlines ease of sampling. The researcher included teachers who have been teaching at the Full-Service School for more than five years. The researcher invited purposely selected participants to participate in the study and the researcher indicated that participation was voluntary. Data was collected through the use of semi-structured 
interviews, open-ended questionnaires, documentation and diary entries. In an attempt to obtain rich data on how cultural diversity influences the Full-Service School, the researcher conducted conversational interviews (semi-structured) with teachers and SGB members, and a semi-structured interview was used for the principal. According to Bertram and Christiansen (2020), various African cultural diversities make use of intimate groups to address concerns found in the community. Thus this type of interview fit impeccably with the location of the Full-Service School. In addition to interviews, the researcher used open-ended questionnaires during the study. The open-ended questionnaires focused on uncovering demographic detail and questions relating to cultural diversity and how it is practised in a Full-Service School. An open-ended questionnaire is used to gain an understanding of underlying reasons, opinions, and motivations of role players. It can also provide insights into the research problem. Furthermore, Open-ended questions may yield more candid information and unique insight for researchers as participants may find them less intimidating than scaled questions. Documentation of the school will include the Code of Conduct and the Vision and Mission Statement of the school. Diary entries were used to understand the participants' initial feelings and expectations during the research process. Diaries involve the reader and provide them with a clear picture as to how the participants feel about cultural diversity in the FullService School as well as supporting the overall procession of the research.

According to Creswell, Hanson, Clark, and Morales (2007), diaries provide a researcher or reader with a clear picture of emotions during the research process. The diaries consisted of two entries per participant completed before and after the research. After each interview, the researcher transcribed all handwritten information into a final record of interviews. Each interview had details of both verbal and non-verbal responses (Creswell et al., 2007) Details of the interviewee included biographical data and a code assigned for each interviewee. The open-ended questionnaires were read in order to make sense of it. Units were then segmented to sentences and phrases using a marker to point then the units were labelled and the label was writing with an arrow. Possible grouping codes were identified and careful attention was given to make sure the codes were linked to the research questions (Henning, van Rensburg and Smith 2004). The documents were analysed to see whether the school's Code of Conduct reflects the acceptance of different cultures. Only relevant parts of the documents were used to enrich the research study. The researcher then looked for relevant themes by using Hettler's Wellness Dimension. After placing the data into themes, the researcher correlated the themes with the interviews to see whether the documents were implemented according to the participants. The diaries were structured under the headings, feelings and expectations. There were two entries, pre-interview and post-interview.

From the meaning attached to the interpretations of themes, logical conclusions were drawn.

All the ethical procedures were followed with participants informed of their right to voluntarily participate or stop the participation out of free will. The participants were assured 
of the confidentiality of data collected and that no reference would be made to their names in the research report.

\section{Findings}

The analysis of research data yielded the following results. These results are discussed according to the themes harvested from the data.

Theme 1: Identity and belonging are influenced by cultural diversity on role players in an FSS school.

An initial objective of the research was to interpret the influence of cultural diversity on role players within a FSS. The findings revealed that teachers did not have a set definition for cultural diversity but rather their own interpretations. This was seen in all the participants' responses. The word "different" was mention in various instances and that teachers should customise their teaching to be equal to all. This finding is consistent with that of Hachfeld, Hahn, Schroeder, Anders and Kunter (2015) who revealed that cultural beliefs relate to aspects of learning and progress and that teachers should not focus on treating all students equally but rather focus on cultural differences and ensure that teachers are trained and encouraged to explore various cultural backgrounds. In this sense the findings showed that teachers at this Full-Service School valued cultural diversity and that it promotes a sense of belonging. Supporting literature highlights psychological benefits of experiencing psychological belongingness in school (Ryan and Deci, 2000; Anderman, 2002).

Themes 2: Educator's knowledge on cultural diversity is learning in a diverse world

A further theme that emerged from the findings is that educators' knowledge on cultural diversity is learning in a diverse world. This study found that the educators placed a lot of emphasis on creating the students to have a mindset of learning in a diverse world. As stated by Member 6, "I have taught the learner that they should respect each other's cultural beliefs". The research revealed that educators at this specific Full-Service School valued the teaching of the diverse world and preparing students to become actively involved in their immediate society. Haddix (2017) and Richmond, Bartell and Dunn (2016) highlight that regardless of the background of teachers, teachers struggle to understand and showcase culturally response practices. This was not the case with this Full-Service School. Role players understood the cultures, the way they behave, the way they act and how to effectively address cultural diversity it in their classrooms. Role players within a Full-Service School from this study view their way of delivering a diverse cultural curriculum subjectively, whether it is through sharing experiences, having cultural celebratory days and code switching as examples.

Theme 3: Cultural diversity influences all wellness dimensions holistically

This study found that educators placed a lot of emphasis on creating the students to have a mindset of learning in a diverse world. As stated by Member 6, "I have taught the learner that they should respect each other's cultural beliefs". The research revealed that educators at this specific Full-Service School valued the teaching of the diverse world and preparing students to become actively involved in their immediate society. The findings correlate with Haddix (2017), A strong relationship between Densmore-James and Macfarlane's work (2013) which showed that culture within a rural school setting should view the child in a holistic manner and educators should advocate for the learners holistically. Haddix (2017) and Richmond, Bartell and Dunn (2016) highlight that regardless of the background of teachers, teachers 
struggle to understand and showcase culturally response practices. In reviewing the findings this was not the case. Role players understood the cultures, the way they behave, the way they act and effectively addressed it in their classrooms. Role players within a Full-Service School from this study view their way of delivering a diverse cultural curriculum subjectively, whether it is through sharing experiences, having cultural celebratory days and code switching as examples.

Theme 4: Teachers, SGB and the principal experience cultural diversity and its influences as hierarchal in an FSS.

The findings suggest that cultural diversity influences the hierarchal structure within a FullService School. The consensus of the findings revealed that role players felt an equal responsibility to address cultural diversity at various levels within a school setting. The findings showed how role players such as teachers adapt their teaching styles to address various cultures within their classrooms. As Member 4 states "I have Zulu speaking learners in my class by adapting and differentiating to be the same level with the learner". This is not seen as a hierarchal structure but rather as a shared vision within this Full-Service School. In agreeance with Letseka (2012) Culture in South Africa, according to Letseka (2012), is seen as a communalistic perspective and not individualistic which is seen as selfish and egocentric.

Theme 5: A community governance framework is proposed to address cultural diversity

An emphasis was placed on the importance of community diversity and Governance. From the findings it became clear that this specific Full-Service School valued the importance of community involvement and taking responsibility as a community to promote cultural awareness and diversity. Viscogliosi et al. (2020) researched the importance of participation of indigenous elders in the community. They concluded that indigenous elders contribute to the community by transmission of values, adding to education and contributing to the holistic wellness within a community. The findings agree with Viscogliosi et al. (2020) as all role players emphases the importance of the indigenous elders and their contributions to the cultural diversity within this Full-Service School.

\section{Themes from Open-Ended Questionaire}

Theme 1: Cultural diversity plays a role on the social acuity of role players in an FSS

According to the study, the behaviour of teachers influences the learners' behaviour. From the findings it became clear that role players within a Full-Service School are being affected in terms of their social wellness due to cultural diversity and the need to address cultural diversity within a Full-Service School. Johann Wolfgang van Goethe highlights this idea perfectly, "Those who know nothing of foreign languages know nothing of their own" (Goethe, 1998:6). In a study completed by Marcellino (2008) revealed that teaching an additional language like English in Indonesia played a huge role not only on the role players within the school but also on the students and in correlation with this study it became evident that there are still language barriers evident in this specific Full-Service School. Marcellino (2008) highlighted that there was a substantial unconstructive influence of the students' cultures and the non-conductive language environment affecting their language acquisition in their study, and this was also evident in this Full-Service School as role players referred to it as being a barrier in the teaching of learners from various languages but it leads to adapting and creative teaching. Interlinked with this findings is a study of Morcom (2017) that showed that social 
awareness is significantly important to academic and social outcomes. This Full-Service School and role players within revealed the lack of funds influences the social outcomes to create and maintain different types of languages and cultural programs.

Theme 2: Educators' knowledge of cultural diversity is defined as 'multifaceted' and unique to each role player in an FSS

The findings show that role players subconsciously move away from rigid and structured ways of teaching. This is evident in the findings where participants stated that before they even follow specific guidelines they consider the attitude of others, then they discuss and interrogate before they blindly teach. This shows that cultural diversity enhances the freedom and flexibility as role players move away from rigid teaching methods.

The findings showed how role players adapt their curriculum to provide equal opportunity for all and how they promote freedom in this Full-Service School setting. One member commented on the freedom of religion and that students and various role-players were given the option to not attend religious practises if they didn't feel comfortable. The findings correlate with the findings of McGuire and Bagher (2010), Lee (1991) and Witmer and Thomas (1992) who posited that spiritual freedom in a school setting is pivotal to enhancing cultural diversity and creating a sense of belonging.

Theme 3: Cultural diversity influences the social wellness dimension

The findings revealed that cultural diversity influences the social wellness dimension within this specific Full-Service School. A study by Dukes (2016) highlights that cultural diversity is influenced by various aspects within the social wellness dimension. Longhi (2014) researched cultural diversity and subjective well-being in England and concluded that there is a correlation between social wellness and well-being.

Theme 4: Teachers, SBG and the principal experience cultural diversity and its influences as historically orientated

It was clear from the data analysis that teachers, SGB and the principal experience cultural diversity and its influences as historically. This was evident in the interviews and questionnaires that the members and participants felt the need to address historical influences as a means to address cultural diversity. It became clear that cultural diversity can't be addressed if one doesn't consider the historical context of the community culture. In a report by UNESCO (2009) it was suggested that that teachers view the material they have in classroom and analyse historical narratives to see which voices are missing. Nussbaumer stated that "not only can CHAT explain situations in terms of dynamic relationships but also reveal social resources as they influence changes in human endeavours and educational practice" (Nussbaumer, 2012:46). Moloney and Saltmarsh's (2016) study concluded that there was a knowledge of different types of diversity will lead to creative and holistic teaching and this correlates with the findings of this study. This means that the teachers in a school like this Full-Service School need to have the knowledge of what has happened historically in that specific context in order to effectively teach and know their own learners.

Theme 5: An equality framework is proposed to address cultural diversity

An equality framework is proposed where role players within this Full-Service school clearly valued equal opportunities for all. It was clear from the diary entries that participants felt a 
need to make the researcher the researcher understand that equality was valued and promoted at this Full-Service school. The findings showed that role players felt that equality is interlinked with showing respect. These findings correlates with findings from Mahaye (2018), Du Toit-Brits et al. (2012) and Schoeman (2012) that equality in education is a defining element of conventional African existence and should therefor guide and direct education and how role players interact with each other.

\section{Themes that Emerged from Document Analysis}

Theme 1: The vision, mission and code of conducts show that policies and documents are influenced by cultural diversity on role players within an FSS

The findings revealed that the vision, mission and code of conduct have been adapted to showcase a cultural diverse approach to this Full-Service School. Meier (2009) argues that the decentralisation of education provided racially defined communities the legal means to preserve their privileges, that schools have been much more successful at meeting the demand for racial desegregation than achieving the ideal of social integration and that messages forthcoming from "race" affect black learners more negatively than other learners in South Africa. However, the researcher disagrees with this statement as it is clear that this FSS showcases cultural diversity as holistically integrated. Educational policies produced since 1994 comments within the policy to consider cultural diversity and has practical examples for education, however, Jansen argues that "policy is not practice, and while an impressive architecture exists for democratic education, South Africa has a very long way to go" (Jansen, 2004:126). The findings correlate with stated Mahaye (2018) that Ubuntu stretches one's mind into a school classroom practice and sparks a new look and transformative navigation and innovation required in our 4th industrial revolution for socio-economic development

Theme 2: The vision, mission and code of conduct show that the educator's knowledge on cultural diversity pivotal and should be promoted through teaching

Research by numerous individuals (Pillay 2004; Carrim \& Soudien 1999; Vally \& Dalamba 1999; Jansen 1998c and Goduka 1998) places doubt on whether attempts at providing equitable and quality education for learners with diverse backgrounds, interests and abilities are successful. The findings revealed in the documentation shows a proactive cultural responsive approach and not an assimilationist approach. Various cultures and histories are shared and encouraged.

Theme 3: The vision, mission and code of conduct show Cultural diversity influences the spiritual wellness dimension in a school setting

The spiritual dimension, as indicated by Hettler (1976), involves the religious dimension in a Full-Service School environment. In South Africa, a culture of different religions is recognised and respected in each school. The social wellness dimension focuses on the way in which one interacts with others in intimate and meaningful relationships and on being an active member in the community (Hettler 1976). Chandler et al. (1992) clearly stated that spiritual wellness is a pinnacle addition to the holistic wellness model and for defining the development of one's spirituality. Miller (2005) defined spiritual wellness musing over the meaning of life, to be tolerant of the beliefs of individuals and to live consistently with our values and beliefs. Furthermore, educators must realise that their role includes being a counsellor and guiding learners to spiritual wellness in the educations system. McGuire and Bagher (2010) 
researched the impact of spiritual labour on the emotions and job satisfaction. McGuire and Bagher (2010) concluded in the study that spirituality can be used to develop culture, this was also noted by Lee (2009) and Witmer (2001). It can then be suggested that spirituality can develop culture, while simultaneously influencing spiritual wellness. The theories revealed from McGuire and Bagher (2010), Lee (2009) and Witmer (2001) assisted the researcher to be able to see that spiritual wellness plays an important role in the overall wellness of a FullService School. McGuire and Bagher (2010) concluded in the study that spirituality can be used to develop culture, this was also noted by Lee (2009) and Witmer (2001). It can then be suggested that spirituality can develop culture, while simultaneously influencing spiritual wellness. The theories revealed from McGuire and Bagher (2010), Lee (2009) and Witmer (2001) assisted the researcher to be able to see that spiritual wellness plays an important role in the overall wellness of a Full-Service School.

Theme 4: The vision, mission and code of conduct shows teachers, SGB members and the principal should experience cultural diversity as a shared goal

The findings correlate with Murithi (2007) that Ubuntu shows a sense of shared destiny between people. The findings shows that each role player felt that they as a school and individual has a shared vision and mission towards cultural diversity. Ubuntu comprises principles such as, "equity, fairness, reciprocity, inclusivity, sense of shared destiny between peoples" (Murithi, 2007: 282). The findings do not agree with Enslin and Horsthemke (2004) and Eliastam (2015) the Ubuntu has negative connotations to development of a community. The findings reveal that without participants realising it, they embody the term Ubuntu and shared the vision and mission to promote cultural diversity in this FSS.

Theme 5: Practising respect is a framework proposed within the vision, mission and code of conducts to address cultural diversity

Lam and Hui (2010) point out that this could conversely hamper the way teachers deal with discipline as teachers of a respective culture might inadvertently adopt inapposite cultural approaches to dealing with discipline. Mokgoro $(1998)$ the following values are defined as key social values of Ubuntu: group solidarity, conformity, compassion, respect. Ubuntu, is also seen by Dekker and van Schalkwyk (1989) as, "a spiritual idea which directs the life experiences of African" (1989:466) and thus a crucial directional marker for validating the research methodology within an African context.

\section{Themes that Emerged from Diary Entries}

Theme 1: Emotional wellness is influenced by cultural diversity on role players in an FSS

Tan, Härtel, Panipucci and Strybosch argue that, "emotions are a crucial factor in cross-cultural interactions and the need to develop both cross-cultural and emotional skills in expatriates is greatest when there is a large cultural gap between the home and host nations" (Tan et al., 2005:4) and further state that culture can direct the emotional state of a person. The findings focuses on cultural diversity and it agrees with Tan et al. (2005) that culture or the topic rather, can have a direct impact on the emotional state of a person. Tan et al. (2005) also identifies a decline in emotional wellness in Asia due to work overload and from the findings 
correlates with this study as cultural diversity influences the workload of teachers and policy makers to ensure that it/they address and promote cultural diversity.

Theme 2: Educator's knowledge on cultural diversity is seen as everyday practice.

Mokgoro (1998) the following values are defined as key social values of Ubuntu: group solidarity, conformity, compassion, respect. Murithi (2007) and Nussbaum (2003) explain that Ubuntu comprises principles such as, "equity, fairness, reciprocity, inclusivity, sense of shared destiny between peoples" (Murithi 2007: 282). Waghid and Smeyers (2012) states that, a directive of national curriculum policy is that indigenous knowledge systems form part of the broad environments of all school areas and subjects. Maisty and Thakrar's (2012) study suggests, without knowledge of the Ubuntu philosophy one might not develop the social responsibilities required by Ubuntu thus not developing social wellness in the community. Understanding the history of their social culture individuals can adjust or improve their own social cultural history - it is the knowledge and familiarity with the culture itself which empowers the reinforcement of positive cultural norms. This study interprets the knowledge and familiarity with the culture of this Full-Service School and the researcher being familiar with the culture within the community and this was evident in the findings.

Theme 3: Cultural diversity influences the emotional wellness dimension within a school setting

The increasing cultural diversity in educational institutions demands that educators teach and manage learners with different cultures, languages and backgrounds that are unknown to them. This in itself can cause anxiety as it is the 'unknown', however more importantly the findings revealed that in this FSS the educators are from similar cultural backgrounds and understand the learners they teach and can culturally adapt their lessons and way of instruction. However, it is still clear that by adapting and ensuring one addresses all the students' cultural needs the educators' emotional wellness will decline. Du Toit (1995) takes the stance that by opening school to all races doesn't automatically ensure mutual respect and understanding for each others' cultures. This is important because it was evident in the findings that educators play a pivotal role in teaching learners about various cultures.

Theme 4: Teachers, SGB members and principal experience cultural diversity as influencing being worrying

The finding revealed that the topic 'cultural diversity' made the participants feel worried about the topic. This was evident prior to the interviews. In a book written by Mooney, Knox and Schacht (2007) it reveals that journal entries illustrated that when personal topics are discussed it might make the participants uneasy as one would consider the social norm. Participants subconsciously know the politically correct responses, but they might be afraid to express their true feelings. In the current study the findings showed that the post diary entries expressed the satisfaction participants felt after the interview, this correlates with Mooney et al. (2007) as one participant said, "I hope I answered it correctly".

\section{Discussion of Findings}

This study explored cultural diversity and its role in a Full-Service School. The increasing cultural diversity in educational institutions forces that role players teach and manage learners and teachers with cultures, languages and backgrounds that are unknown to them. 
This study focused on the role cultural diversity might play on role players within a FullService School.

Findings from the semi-structured interviews revealed that role players' identity and sense of belonging is influenced by cultural diversity. Additionally, the educator's knowledge on cultural diversity is learning in a diverse world and that cultural diversity influences all wellness dimensions holistically. Teachers, SGB and the principal experience cultural diversity and its influences as hierarchal in an FSS and that a community governance framework is proposed to address cultural diversity.

Themes from the open-ended questionnaires revealed that the role players' social acuity is influenced by cultural diversity in an FSS. The educator's knowledge of cultural diversity is defined as 'multifaceted' and unique to each participant. Cultural diversity influences the social wellness dimension at an FSS. Teachers, SBG and the principal experience cultural diversity and its influences as historically orientated. Finally, an equity framework is proposed to address cultural diversity

Themes from the document analysis revealed that the vision, mission and code of conduct shows school policies and documents are adapted to promote cultural diversity, the educator's knowledge of cultural diversity is pivotal and should be promoted through teaching and that cultural diversity influences the spiritual wellness dimension in a school setting. Additionally, the vision, mission and code of conduct show that teachers, SGB members and the principal should strive for cultural diversity as a shared goal. Finally, practising respect is a framework proposed in the vision, mission and code of conducts to address cultural diversity

Findings from the diary entries revealed that the role players' emotional wellness is influenced by cultural diversity in an FSS and the educators' knowledge on cultural diversity is seen as everyday practice. Furthermore it became evident that cultural diversity influences the emotional wellness dimension within a school setting. Finally, teachers, SGB members and the principal experience cultural diversity as influencing their physical wellness and participants proposed a wellness framework to address cultural diversity by establishing a community governance framework, promoting equality and by practising and teaching 'respect'.

\section{Conclusion}

Cultural diversity and its influence on role players within a Full-service school from a wellness perspective remains a subject of discussion and from the findings can influence wellness within a Full-service school holistically. All role players were influences by cultural diversity and if not addressed influences the school culture, teaching and learning. Although this article cannot be regarded as generalised on all Full-service School, but it provides a basis for extended research and discussion for role players within Full-service School s in South Africa or in similar context.

\section{Recommendations}

Through the voices of the role players, the study recommends that policy makers and education officials give the necessary provision to schools; especially in terms of curriculum adaptation, knowledge and funding.

The study recommends that educators be trained on cultural diversity and Ubuntu and how to effectively teach and celebrate each culture. This can be done through training courses, 
workshops, visits and staff development programmes in which they invite people with knowledge and expertise in cultural diversity and or various cultures.

Teachers, SGB and the principal experience cultural diversity and its influences as hierarchal in an FSS and that a community governance framework is proposed to address cultural diversity.

The researcher believes that workshops could be established through the Department of Education to improve the way in which Full-Service Schools view cultural diversity.

An equity framework is proposed to address cultural diversity.

Compliance with Ethical Standards

Conflict of interest Author A declares that he/she has no conflict of interest.

Ethical Approval All procedures performed in studies involving human participants were in accordance with the ethical standards of the institutional and/or national research committee and with the 1964 Helsinki declaration and its later amendments or comparable ethical standards.

Informed Consent Informed consent was obtained from all individual participants included in the study.

\section{References}

[1] Ames, H., Glenton, C. and Lewin, S. (2019) Purposive sampling in a qualitative evidence synthesis: a worked example from a synthesis on parental perceptions of vaccination communication. BMC Med Res Methodol, 19(26)

[2] Anderman, E. M. (2002). School effects on psychological outcomes during adolescence. Journal of Educational Psychology, 94(4), pp. 795-809

[3] Arnolds, Matthews. 1869. Culture and Anarchy. London

[4] Bertram, Carol and Christiansen, Iben. (2019). Understanding Research: An introduction to reading research. Van Schaik Publishers

[5] Burton, C.R. (1980) Academic Culture. Institution for social and policy studies. Yale University: New Haven

[6] Carrim ,N and Soudien, C. (1999) Critical Anti-Racism in South Africa. In S May (ed) Critical Multiculturalism: Multicultural and Anti-Racist Education. London: Falmer Press

[7] Chandler, C. K., Holden, J. M., and Kolander, C. A. (1992). Counselling for spiritual wellness: Theory and practice. Journal of Counselling \& Development, 71, pp. 168175.

[8] Creswell, J. W., Hanson, W. E., Clark P. V. L. and Morales, A. (2007) Qualitative Research Designs: Selection and Implementation. The Counselling Psychologist, 35(2) pp. 236264 
[9] Danso R. (2018) Cultural competence and cultural humility: A critical reflection on key cultural diversity concepts. Journal of Social Work, 18 (4), pp. 410-430

[10] Dekker, E. I and Van Schalkwyk, O. J (eds.). (1989) Modern Education Systems. Durban, Butterworths. Densmore-James and Macfarlane's work (2013)

[11] Department of Education. (2001). Education White Paper 6 on Special Needs Education: Building an Inclusive Education and Training System. Department of Education, Pretoria: Government Printer.

[12] Du Toit, D. (1995) A Sociological analysis of the extent and influence of professional socialization on the development of a nursing identity among nursing students at two universities in Brisbane, Australia. Jan Leading Global Nursing Research, 21(1), pp. 164-171

[13] Du Toit-Brits, C., Potgieter, F.J. and Hongwane, V. (2012) Distance education as a 'weness': A case for uBuntu as a theoretical framework. Progressio, 34(2), pp. 3-16

[14] Dukes, H. (2016). "Cultural Effects On Wellness As It Applies To Society And The Individual: An International Comparison Of Germany And The United States Of America", Honors Projects. 568. http://scholarworks.gvsu.edu/honorsprojects/568

[15] Eliastam, J. (2015) Exploring ubuntu discourse in South Africa: Loss, liminality and hope. Verbum et Ecclesia.

[16] Enslin, P and Horsthemke, K. (2004) Can Ubuntu Provide a Model for Citizenship Education in African Democracies?. Comparative Education.

[17] Fairhurst, A.E., and Good, L.K. (1991) The ethnographic case study: An experiential problem solving approach. In W. Wheatley and G. Gosenpud (Eds.) Developments in Business Simulation and Experiential Exercise, pp. 16-18.

[18] Gay, G. (2013). 'Teaching To and Through Cultural Diversity', Curriculum Inquiry, 43(1), pp. 48-70

[19] Goduka, I. N. (1998). 'Linguistic and cultural diversity implications for learning, educating and curricular transformation'. South African Journal of Higher Education, 12 (1), pp. 34-43

[20] Van Goethe, J. W. (1998):6

[21] Hachfeld, A., Hahn, A., Schroeder, S., Anders, Y. and Kunter, M. (2015) Should teacher be colourblind? How multicultural and egalitarian beliefs differentially relate to aspects of teachers' professional competence for teaching in diverse classrooms. Teaching and Teacher Education, 48, pp. 44-55

[22] Haddix, M. M. (2017) 'Diversifying Teaching and Teacher Education: Beyond Rhetoric and Toward Real Change', Journal of Literacy Research, 49(1), pp. 141-149

[23] Harmon, H. L. and Schafft, K. (2009). Rural School leadership for collaborative community development. The Rural Educator, 30(3), pp. 4-9

[24] Harmon, Hobart \& Schafft, Kai. (2018). 'Rural School Leadership for Collaborative Community Development'. The Rural Educator.

[25] Henning, E., van Rensburg, W., and Smith, B. (2004) Finding your way in qualitative research Publisher: Van Schaik 
[26] Hettler, Bill. (1976) “The Six Dimensions of Wellness.” National Wellness Institute.

[27] http://www.hettler. com/sixdimen. htm.

[28] -1980. Wellness Promotion on a University Campus. Family \& Community Health, 3(1) pp. 77-95

[29] -1984. Wellness: Encouraging a Lifetime Pursuit of Excellence. Health Values, 8(4), pp. 13-17

[30] Hinde, E. R. (2004). School culture and change: An examination of the effects of school culture on the process of change. Essays in Education, 11.

[31] Jansen, J. (1998c). Curriculum reform since apartheid: Intersections of policy and practice in the South African transition. Journal of Curriculum Studies, 31(1), pp. 5767

[32] Jansen, J. (2004) Evaluating transitions. Review essay. Pedagogy, Culture and Society, $1(2)$, pp. 309-312.

[33] Jenkins, J.H. (1987) Culture, emotion, and Psychopathology. In Emotion and culture by Kitayama, S \& Markus, H, R. (1994). American Psychological Association, Washington.

[34] Lam, S.K.Y. \& Hui, E.K.P. (2010) Factors affecting the involvement of teachers in guidance and counselling as a whole-school approach. Journal of Guidance \& Counselling, 38(2) pp. 219-234.

[35] Lee, J. (2009) 'Not if but when pedagogy collides with culture in Singapore, Pedagogies', An International Journal, 5(1), pp. 17-26

[36] Letseka, M.(2012) In Defence of Ubuntu. Stud Philos Educ 31, pp. 47-60 (2012)

[37] Lindström, B. and Eriksson, M. (2011) 'From health education to healthy learning: Implementing salutogenesis in educational science', Scandinavian Journal of Public Health, 39(6), pp. 85-92.

[38] Longhi, S. (2014) 'Cultural diversity and subjective well-being'. IZA J Migration 3, 13

[39] Mahaye, N. E. (2018). The philosophy of Ubuntu in education.

[40] Maistry, M. and Thakrar, J. (2012). Educating students for effective community engagement: Student perspectives on curriculum imperatives for universities in South Africa. South African Review of Sociology, 43, pp. 58-75

[41] Marana, M. (2010) 'Culture and Development Evaluation and prospect', UNESCO Etxea. Working paper No.1.

[42] Marcellino, M. (2008) 'English Language Teaching in Indonesia: A Continuous Challenge in Education and Cultural Diversity', TEFLIN Journal: A publication on the teaching and learning of English, 17(1), pp. 19

[43] Maree, K. (2007) First Steps in Research. Van Schaik, Pretoria.

[44] Matarasso, F. (2007) Common ground: 'Cultural action as a route to community development'. Community Development Journal, 42(4), pp. 449-458

[45] McGuire, D. and Bagher, M. (2010) 'Diversity training in organisations: An introduction', Journal of European Industrial Training, 34(4), pp. 93-505 
[46] McMahon, T.J., Ward, N.L., Kline Pruett, M., Davidson, L. \& Griffith, E.H. (2000) 'Building full-service schools: Lessons learned in the development of interagency collaboratives', Journal of Education and Psychological consultation, 11(1): pp. 65-92

[47] Miller, J, G. (2005) 'Essential role of culture in developmental psychology', Special Issue: New Horizons in Developmental Theory and Research, 109, pp. 33-41

[48] Mokgoro, Y. (1998) 'Ubuntu and the law in South Africa', Buffalo Human Rights Law Review, 15, pp. 1-6.

[49] Moloney, R., and Saltmarsh, D. (2016) 'Knowing Your Students' in the Culturally and Linguistically Diverse Classroom. Australian Journal of Teacher Education, 41(4)

[50] Mooney, L. A., Knox, D., and Schacht, C. (2007) 'Understanding Social Problems'. 5th Edition. Thomson Wadsworth. Thomson Higher Education. Belmont, CA: USA.

[51] Morcom, L. A. (2017) 'Self-esteem and Cultural Identity in Aboriginal Language Immersion Kindergarteners', Journal of Language, Identity \& Education, 16(6), pp. 365-380, DOI: 10.1080/15348458.2017.1366271

[52] Motitswe, J. M. C. (2011) 'Teaching and learning methods in inclusive methods in inclusive classrooms in the foundation phase'. Master's dissertation. Pretoria: University of South Africa

[53] Murithi, T. (2007) African approaches to building peace and social solidarity. African Journal on Conflict Resolution.

[54] Nussbaum, M. (2003) 'Beyond the Social Contract: Toward Global Justice', The Tanner Lectures Human on Values. http://www.tannerlectures.utah.edu/lectures/documents/volume24/nussbaum_20 03.pdf

[55] Nussbaumer, D. (2012). An overview of cultural historical activity theory (CHAT) use in classroom research 2000 to 2009. Educational Review.

[56] Ortega-Williams, A., Crutchfield, J. and Hall, J. C. (2019) 'The colourist-historical trauma framework: Implications for culturally responsive practice with African Americans', Journal of Social Work. doi: 10.1177/1468017319890083.

[57] Peterson, K. and Deal T. (1998) 'How leaders influence the culture of schools'. Educational Leadership, 56 (1), pp. 28-30

[58] Hinde, Elizabeth. (2004). 'School Culture and Change: An Examination of the Effects of School Culture on the Process of Change'. 11.

[59] Richmond, G., Bartell, T. and Dunn, A. H. (2016) 'Beyond "Tinkering”: Enacting the Imperative for Change in Teacher Education in a Climate of Standards and Accountability', Journal of Teacher Education, 67(2), pp. 102-104

[60] Ryan, R. M. and Deci, E. L. (2000) Self-Determination Theory and the Facilitation of Intrinsic Motivation, Social Development, and Well-being. American Psychologist, 55(1), pp. 67-78

[61] Schein, E, H. (1984) 'Culture as an environmental context for careers', Journal of Organizational Behaviour, 5(1), pp. 71-81 
[62] Schoeman, M. (2012) 'A philosophical view of social transformation through restorative justice teachings -a case study of traditional leaders in Ixopo, South Africa'

[63] Spradley, J. P. (1979) 'The ethnographic interview'. New York, Holt, Rinehart and Winston.

[64] Steenkamp, U. 2012. A retrospective study on transforming a mainstream school into a full-service school. Masters Degree dissertation: University of Pretoria

[65] Tan, J. A. C., Härtel, C. E. J., Panipucci, D. and Strybosch, V. E. (2005), "The effect of emotions in cross-cultural expatriate experiences", Cross Cultural Management: An International Journal, 12(2), pp. 4-15

[66] Kim, H., Sherman, D. and Taylor, S. (2008). 'Culture and Social Support'. The American psychologist, 63, pp. 518-26

[67] Turnbull, C. M. (1961). The forest people. New York: Simon \& Schuster.

[68] Turnbull, C. M. (1972). The mountain people. New York: Simon \& Schuster.

[69] UNESCO World Report Investing in Cultural Diversity and Intercultural Dialogue Published in 2009 by the United Nations Educational, Cultural and Scientific Organization Vally, Salim \& Dalamba, Y. (2002). Racial Integration" and Desegregation in South African Public Secondary Schools.

[70] Viscogliosi, C., Asselin, H., Basile, S. , Borwick, K., Couturier, Y., Drolet, M., Gagnon, D., Obradovic, N., Torrie, J., Zhou, D, and Levasseur, M. (2020). 'Importance of Indigenous elders' contributions to individual and community wellness: results from a scoping review on social participation and intergenerational solidarity'. Can J Public Health, 111, pp. 667-681

[71] Vygotsky, L.S. (1978). Mind in Society: The Development of Higher Psychological Processes. Cambridge Massachusetts: Harvard University Press.

[72] Waghid, Y. and Smeyers, P. (2012). 'Taking into account African Philosophy: An impetus to amend the agenda of philosophy of education'. Educational Philosophy and Theory, 44, pp. 1-5

[73] Weeks, F. (2011). The quest for a culture of learning: a South African schools perspective. South African Journal of Education. 32. pp. 1-14

[74] Witmer, J. M. and Thomas J. S. (1992). 'A Holistic Model for Wellness and

[75] Prevention over the Life Span.' Journal of Counselling \& Development, 71 (2), pp. 14048 